\title{
Functionalization of medical textiles
}

\author{
Natalia Sadretdinova1, Sergey Bereznenko', Larisa Bilotska1, Maria Pawlowa², \\ Halina Szafranska2, ${ }^{2}$, Vitalii Bakal ${ }^{3}$, Natalia Bereznenko ${ }^{3, *}$ \\ ${ }^{1}$ Kyiv National University of Technologies and Design, Kyiv, Ukraine \\ 2 Kazimierz Pulaski University of Technology and Humanities in Radom, Radom, Poland \\ ${ }^{3}$ State Research Institute of the Ministry of Internal Affairs of Ukraine, Kyiv, Ukraine \\ * Corresponding author E-mail address: h.szafranska@uthrad.pl,nmbereznenko@gmail.com
}

\section{INFO}

CDAPT, ISSN 2701-939X

Peer reviewed article

2020, Vol. 1, No. 2, pp. 88-95

DOI: 10.25367/cdatp.2020.2.p88-95

Received: 11 May. 2020

Accepted: 21.07.2020

Available online: 23 November 2020

\section{Keywords}

medical clothing,

herbal modifiers,

antimicrobial properties,

energy-information state of organs

\begin{abstract}
An important basis for the creation of medical clothing is realization of the influence of various factors that arise in the interaction of elements of the system "man-clothes-production environment". Given the increasing technogenic burden on health of both medical staff and hospital patients, the assessment of the role of medical clothing in forming the energy balance of direct consumers is extremely relevant. Previous studies have experimentally confirmed the presence of energy effects of textile materials on the human body. However, determination of the nature of the impact is a complex task, which solution depends on a number of factors, such as the raw material composition, its structure, surface characteristics, etc. The purpose of our paper is to study the development of textile multifunctional materials for medical purposes and to study their energy-information impact on the human body. The following tasks have been solved in the course of the study. For use in the medical field, several samples of textile materials with antimicrobial properties, modified by herbal preparations, were obtained. Properties of textile materials that determine the possibility of their use in medical practice have been investigated. The influence of the experimental samples on the functional state of the organs and systems of human organs by use of the methods of information-wave therapy is evaluated.
\end{abstract}

(C) 2020 The authors. Published by CDAPT.

This is an open access article under the CC BY-NC-ND license https://creativecommons.org/licenses/ peer-review under responsibility of the scientific committee of the CDAPT. 


\section{Introduction}

Textile based products are widely used in modern medicine. First and foremost, it is clothing worn by patients and healthcare professionals, towels and tissues to hold and clean the fluid, wipes to maintain sterility during surgery, as well as interior items and linens. Considering the particularities of the consumption environment, textiles can be a potential source of infection by holding microorganisms and transmitting them during human contact. This is what we are watching in the worldwide pandemic caused by COVID 19, when personal antimicrobials for doctors and the general public have become one of the most important means of preventing the spread of infection. Therefore, as a response to the challenge of the present day, research related to antimicrobial treatments in the field of medical textiles is intensifying.

Analysis of research in the field of functionalization of medical textiles shows that today different ways of giving antimicrobial properties to textile materials have been developed and successfully used. The literature provides data on the bacteriostatic effect of textile materials on impregnation with a mixture of neomycin salts with propionic, tartaric, phthalic, stearic and some other acids, which were dissolved in water, butanol or methanol and applied to the material by spraying solutions. However, the antimicrobial action of such materials is short-lived. As biocides, metal salts have become quite widespread. The use of copper salts as an antibacterial agent leads to the dyeing of the textile material in yellow-green color. The use of zinc salts is limited by their weak biocidal action, and the salts of mercury, tin, arsenic increase toxicity to humans [2,3]. Much attention is drawn to the functional activity of silver nanoparticles in terms of giving both bactericidal and bacteriostatic properties to various materials and products, but there are problems, caused by the leaching of ions into wastewater, which leads to environmental pollution [4].

One of the ways to increase the durability of antimicrobial processing on textiles is microencapsulation. Biocides are placed in nano-sized containers (cyclodextrin, liposomes - vesicles). In the case of vesicles, pathogenic bacteria that have an affinity for the vesicles attack them, destroy the vesicle membrane, and release molecules or nanoparticles of the biocide from it [10].

Finishing of textiles with hydrophobic agents (for example, silicones) can reduce the impact of microorganisms on materials by reducing the amount of adsorbed moisture, but does not completely eliminate them [5].

In the worsening global environmental crisis, another promising area of antimicrobial properties is the socalled "green technology", which involves the production of new products with minimal environmental damage [6].

Thus, to obtain products with antimicrobial properties they use materials based on bast fibers, whose unique natural properties can be supplemented or enhanced by surface modification [7]. Natural dyes and pigments derived from plants, insects, animals and minerals also have antimicrobial activity [8]. Plant extracts can be used in the form of reducing agents in nanomodification, as well as independently, in the form of impregnations or sprays [9].

As we can see, modern science offers a large number of options for providing antimicrobial properties to textile materials. Given the scientific uncertainty and the emergence of more and more new data on the early signs of harm and the potential adverse health effects that may be associated with antimicrobial treatments, the precautionary approach seems to be most appropriate. There is a need to clarify information on the effect of physically or chemically modified materials on the human body. These are medical products whose operation involves many risk factors and it is therefore important to understand how the presence of a particular treatment will affect the overall condition of the potential consumer of such products in the traditional operating environment.

Nowadays, in the field of medical diagnostics, energy-information wave medicine is becoming more widespread, its main provisions are based on quantum mechanics and theoretical physics [10]. There are known about twenty methods and devices that use various physical effects: electropunctural 
diagnostics, electromagnetic wave therapy with the use of other energy types (UV radiation, torsion fields), SCENAR-therapy, mineral-, color-, sound and spectral therapy etc.

Previous studies [11], carried out using the methods of electrowave diagnostics, have detected a complex effect of materials and their components on the functional state of organs and organ systems. This indicates the significant role of materials for the clothes manufacturing, as important mean of protecting people from aggressive environment, pathogens of internal and external origin. In this case, the information-wave nature of the interaction of the elements of the system "man-clothes-microbial environment" can be realized due to standing waves that occur when interfering with the traveling wave from the pathogen and the oncoming wave reflected from the material. Therefore, conducting a comparative analysis of the results of registration of the functional state of the human body under the influence of the studied textile material and without its influence makes it possible to assess the degree of safety of using this material for the functioning of the body of potential consumers in the production environment.

Considering these aspects, the purpose of the study was the functionalization of medical textiles by providing them with long-lasting antimicrobial properties based on "green technologies" and the study of their energy-information impact on the human body.

The following tasks have been solved in the course of the study. For use in the medical field, several samples of textile materials with antimicrobial properties, modified by herbal preparations, were obtained. Properties of textile materials that determine the possibility of their use in medical practice are investigated. The influence of experimental samples on the functional state of organs and systems of human organs by use of information-wave therapy methods was evaluated.

\section{Method}

\subsection{Description of the Subject of Research}

A review of the literature has revealed that the main material used in the manufacture of medical clothing at present is mixed textile fabrics containing cotton. Therefore, as a textile basis for the application of the modifying agent, cotton fabric (65 PE / 35 of cotton) of weave was selected with a surface density of $125 \mathrm{~g} / \mathrm{m}^{2}$.

An antimicrobial drug used to modify the textile fabric is a peony infusion solution patented as an antimicrobial drug that have an active effect on gram-positive, gram-negative bacteria and fungi such as Staphylococcus aureus, Candida albicans and Bacillus subtilis [12]. The recommended concentration of the solution is $0.05 \mathrm{~g} / \mathrm{l}$.

\subsection{Methods and Devices for Antimicrobial Coating}

Traditional antimicrobial coatings can generally be considered as polymeric matrices. They are usually applied to the textile material by spraying or impregnating with a solution, followed by a drying process to remove the solvent. A common problem for such antimicrobial coatings is the instability to repeated wet treatments, which may be caused by limited adhesion.

To compare the stability of the antimicrobial properties of the textile material added as a result of the modification, two methods of applying the modifier to the textile material were used.

To provide antimicrobial treatment in the first way, aqueous nano-solution with infusion of peony medicinal is sprayed on the surface of the sample tissue using a steam brush.

The second method involves the impregnation of the textile material with citric acid and the subsequent spraying of the medicinal peony nano solution. Citric acid (2-hydroxy-1,2,3-propantricarboxylic acid, $\mathrm{C}_{6} \mathrm{H}_{8} \mathrm{O}_{7}, \mathrm{HOOC}-\mathrm{CH}_{2}-\mathrm{C}(\mathrm{OH}) \mathrm{COOH}-\mathrm{CH}_{2}-\mathrm{COOH}$ ) with a working concentration of $0.96 \mathrm{~g} / \mathrm{I}$ was used for the preliminary impregnation of the textile. The essence of the modification is to create the necessary conditions for the reaction between the anhydride modifying agent (acid) and cotton cellulose textile 
material. For this purpose, the fabric is filled with a solution of citric acid of a given concentration. After stirring for $30 \mathrm{~min}$. at $20{ }^{\circ} \mathrm{C}$, the acid solution is drained, the fabric is placed in a vessel and dried at $50{ }^{\circ} \mathrm{C}$ in an oven for 4 hours. After drying, the thermochemical reaction between the acid and the cellulose occurs by raising the temperature to $120{ }^{\circ} \mathrm{C}$, at which the acid is converted to the anhydride. Processing time is 2 hours. After cooling, the reaction products are washed with distilled water until neutral to remove excess acid. After drying, an aqueous solution of the herbal preparation - peonies drug concentration of $0.05 \mathrm{~g} / \mathrm{I}$ nano solution - was sprayed with a Philips GC361 / 20 Steam \& Go steam brush, repeating the first method. To dry the tissue samples, a ShS-3 drying cabinet was used to provide drying of the materials at a predetermined temperature $\left(10^{\circ} \mathrm{C}\right.$ above room temperature and up to $200^{\circ} \mathrm{C}$ ).

Spraying was carried out by use of Philips GC361 / 20 Steam \& Go household steam brush used for safe ironing of all kinds of fabrics, with a steady supply of $22 \mathrm{~g} / \mathrm{min}$ [13]. To check the stability of the obtained antimicrobial effect, the samples were washed in an automatic washing machine according to the method of GOST ISO 6330-2011.

\subsection{Methodology of Energy-Information Impact Assessment}

Today, scientists [14-16] have proved the importance of biologically active points and biologically active zones in the perception of the influence of environmental factors: meteorological, solar activity, various electromagnetic fields, etc. And these achievements are already being used to create the latest functional clothing.

Previous studies conducted in collaboration with researchers of Khmelnitsky National University have shown that use of the hardware-software diagnostic complex "Intera-DiaCor" (Register of Medical Technology of Ukraine No $3277 / 2004$ dated 30.10.2009) makes it possible to register the parameters of zonal conductivity from biologically active areas of the body that are functionally connected with organs, and to evaluate the functional status of the latter and the body as a whole at the cellular level [17].

The study was conducted according to the method described in [11]. According to the method, after two complete cycles of diagnosis, the results of diagnostics of the functional state of organs and systems of the human body were compared without the influence of the analyzed fabric and with it. The results of the diagnosis at the Intera-DiaCor are displayed on the monitor in the form of histograms showing the three main states of organs and systems of the human body: energy lability (normal state); energy instability (instability of energy processes in the body); energy failure (suppression of energy processes).

According to the developed methodology, the level of negative and positive energy-wave influence is suggested to be estimated by the numerical value of the comfort factor $\mathrm{K}_{\mathrm{k}}$ :

$$
\mathrm{KK}=\frac{\mathrm{Kc}-\mathrm{KH}}{\mathrm{Kc}} \cdot 100 \% \text {, }
$$

where $\mathrm{K}_{H}$ - the number of organs (organ systems) of the human body, in which functional and energy state there were negative changes caused by the influence of the material; $\mathrm{Kc}$ - the number of organs (organ systems) of the human body that have been diagnosed.

The methodology for conducting comfort studies at the Intera-DiaCor APC is described in [17] and patented [18].

\section{Results}

In order to detect the effect of modified textile material on the human body, the functional state of the human body was investigated by use of the Intera-DiaCor APC. The study was performed with the involvement of two young people, whose functional state of the organism at the time of the study was not characterized with significant deviations. This number is sufficient because the determination of the 
functional state of the human body using the Intera-DiaCor APC has high accuracy (relative warranty error does not exceed 5\%).

a

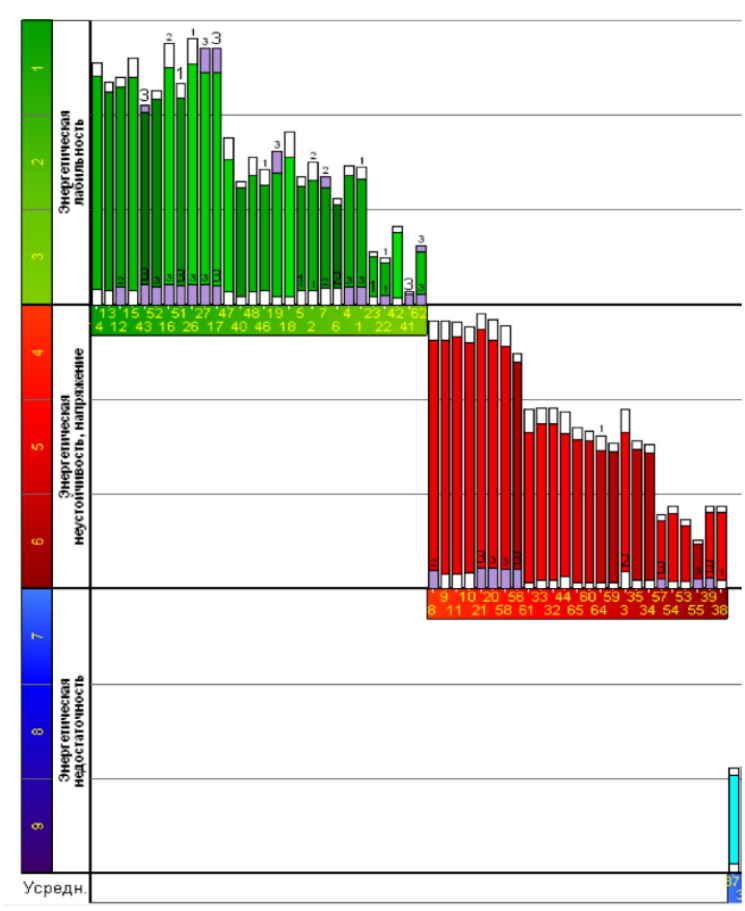

C

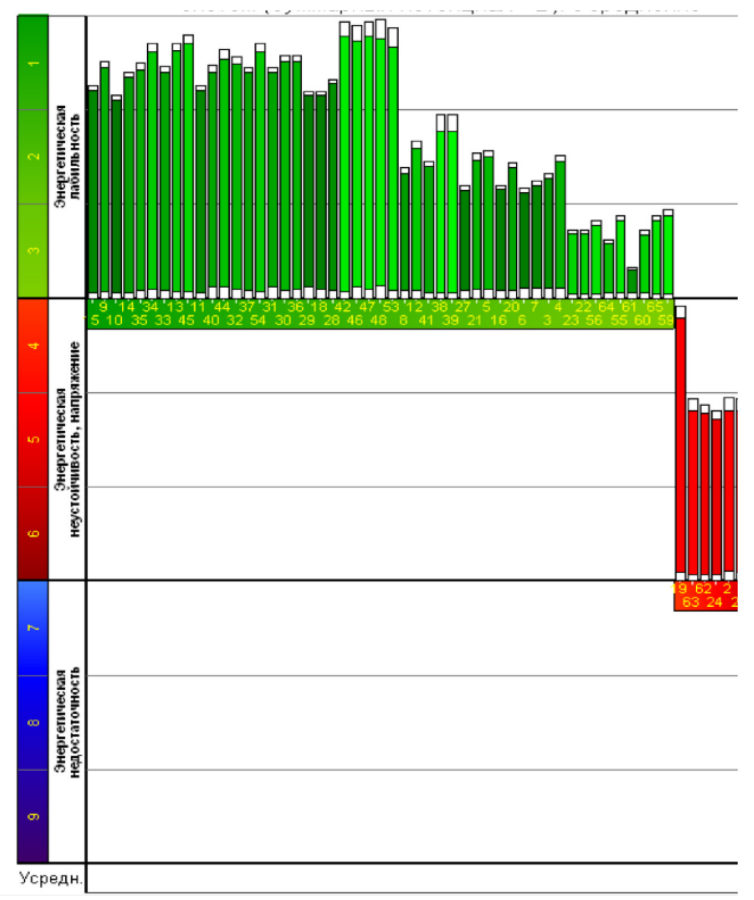

b

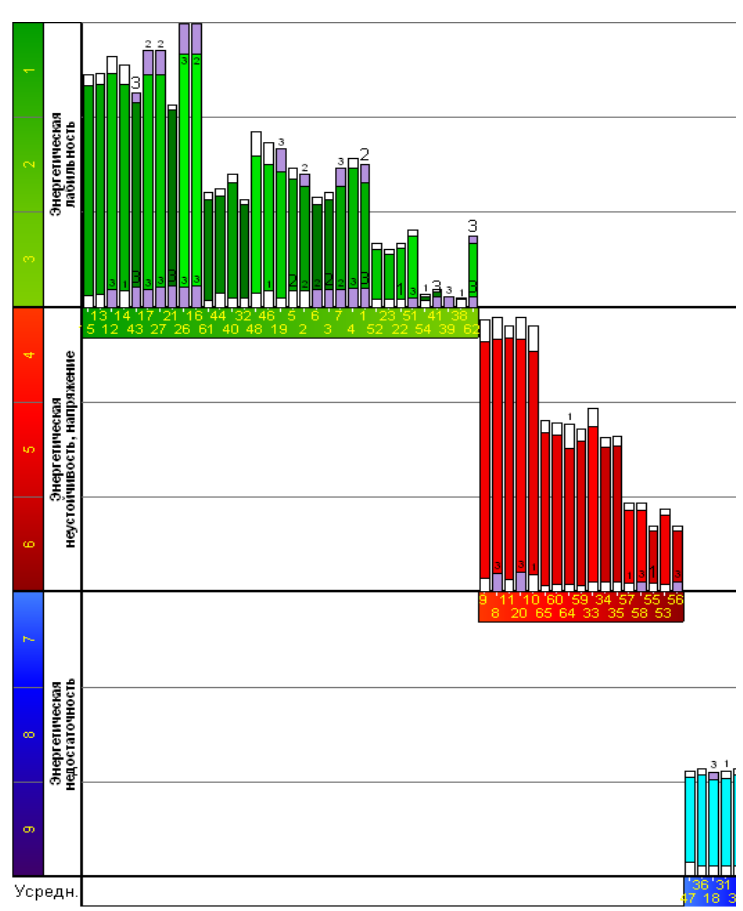

d

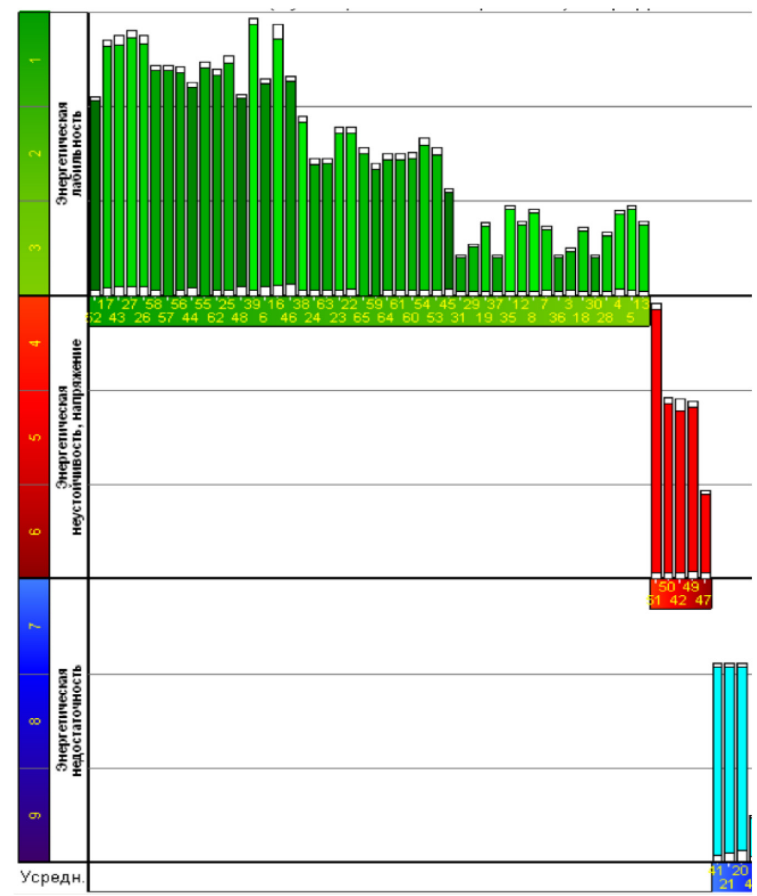

Fig. 1. Histograms of the Energy and Functional State of Organs: (a) - a person without a sample of material, C1; (b) - a person with an unmodified sample of material, C2; (c) - the person with the sample modified in the first way, C3; (d) - the person with the sample modified in the second way, C4.

The studies were conducted in four environments of interaction between humans (subjects) with textile material:

C1 - a person without a sample of material;

C2 - a person with an unmodified sample of material; 
C3 - a person with a sample modified by spraying an aqueous peony drug solution (first method);

C4 - a person with a sample modified by impregnation of the textile material with citric acid and subsequent spraying of the medicinal peony nano solution (second method).

After two complete cycles of diagnosis, the results of the diagnostics of the functional state of the organs and systems of the human body were compared without the influence of the test cloth and with it. Examples of the obtained histograms are shown in Figure 1.

On the basis of the obtained histograms, the total number of organs and systems of organs of the human organism, which are in different energy states: energy lability (green column), energy instability (red column) and energy insufficiency (blue column) without the influence of the material and under their influence on the investigated persons was calculated. Based on these data, the coefficient of comfort was calculated using the formula above. The results are summarized in Table 1.

Table 1. Results of the calculation of the level of energy information impact of textile antimicrobial materials on the functional state of the human body.

\begin{tabular}{|c|c|c|c|c|c|c|c|c|}
\hline \multirow{3}{*}{$\begin{array}{l}\text { Types of test } \\
\text { environments }\end{array}$} & \multicolumn{6}{|c|}{ Number of human organs in condition: } & \multirow{2}{*}{\multicolumn{2}{|c|}{ Comfort coefficient }} \\
\hline & \multicolumn{2}{|c|}{ energy lability } & \multicolumn{2}{|c|}{ energy instability } & \multicolumn{2}{|c|}{ energy failure } & & \\
\hline & person 1 & person 2 & person 1 & person 2 & person 1 & person 2 & person 1 & person 2 \\
\hline $\mathrm{C} 1$ & 28 & 37 & 25 & 0 & 12 & 28 & 1.00 & 1.00 \\
\hline $\mathrm{C} 2$ & 33 & 37 & 17 & 0 & 15 & 28 & 1.08 & 1.00 \\
\hline C3 & 49 & 47 & 10 & 2 & 6 & 16 & 1.32 & 1.15 \\
\hline C4 & 46 & 60 & 5 & 5 & 14 & 0 & 1.28 & 1.35 \\
\hline
\end{tabular}

As it can be seen from the table, an unmodified sample of material (C2) has a minor effect on the functional state of the organism, which makes it possible to weigh it inert to the effect on the body. At the same time, the samples modified with the nanoparticle of peony medicinal, applied in the first and second methods (C3, C4), have a significant effect on the correlation of the number of organs in different energy states. At the same time, there is a tendency to increase the number of organs in the state of energy lability and decrease their number in the states of energy instability and insufficiency.

To determine the resistance of antimicrobial treatments to the effects of service loads, similar studies were conducted for samples of modified materials after three washing cycles. The results are shown in Table 2.

Table 2. Results of the calculation of the level of energy information impact of textile antimicrobial materials on the functional state of the human body after three washing cycles.

\begin{tabular}{|c|c|l|l|l|l|l|c|c|}
\hline \multirow{2}{*}{$\begin{array}{c}\text { Types of test } \\
\text { environments }\end{array}$} & \multicolumn{9}{l|}{ Number of human organs in condition: } & \multicolumn{2}{l|}{ Comfort coefficient } \\
\cline { 2 - 9 } & \multicolumn{2}{l}{ energy lability } & energy instability & energy failure & & \multicolumn{2}{c|}{} \\
\cline { 2 - 9 } & person 1 & person 2 & person 1 & person 2 & person 1 & person 2 & person 1 & person 2 \\
\hline C1 & 28 & 37 & 25 & 0 & 12 & 28 & 1.00 & 1.00 \\
\hline C2 & 30 & 37 & 20 & 0 & 15 & 28 & 1.03 & 1.00 \\
\hline C3 & 37 & 45 & 18 & 4 & 10 & 16 & 1.14 & 1.12 \\
\hline C4 & 45 & 52 & 10 & 13 & 10 & 0 & 1.26 & 1.23 \\
\hline
\end{tabular}

A slight decrease in lability indicates that the result of the modification of the tissue with a solution of peony drug positive effect on the energy-functional state of the body, is quite resistant to the effects of washing. After three cycles of washing, citric acid modified with peony solution (C4) exert a more active effect on the organism of the subjects compared to those modified only with peony solution (C3).

This can be explained by the fact that under the action of citric acid increases the size of the capillaries inside the cellulose fibers, which in the further processing are filled with modifiers, extending the life of protective textiles. 
To study the dynamics of the change in the coefficient of comfort for different test environments before and after washing, the diagrams are shown in Fig. 2. In determination of the tendency of change in comfort the control sample (C2) was not considered, since it does not have a clear effect on the human body.

a

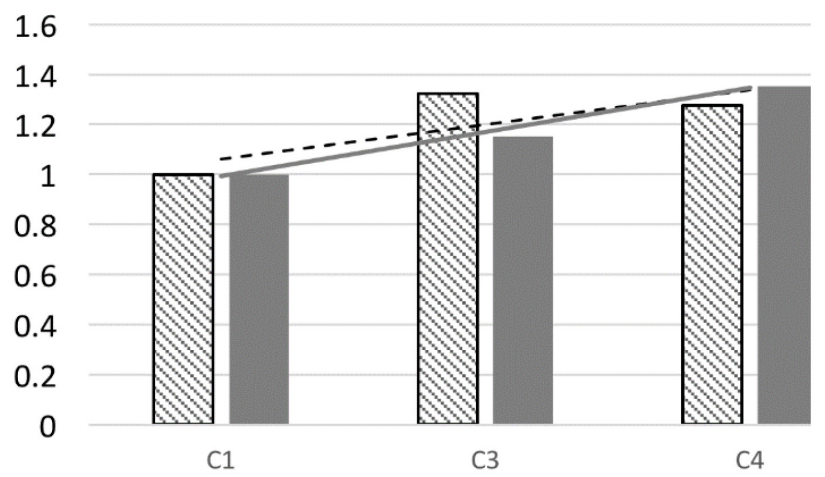

b

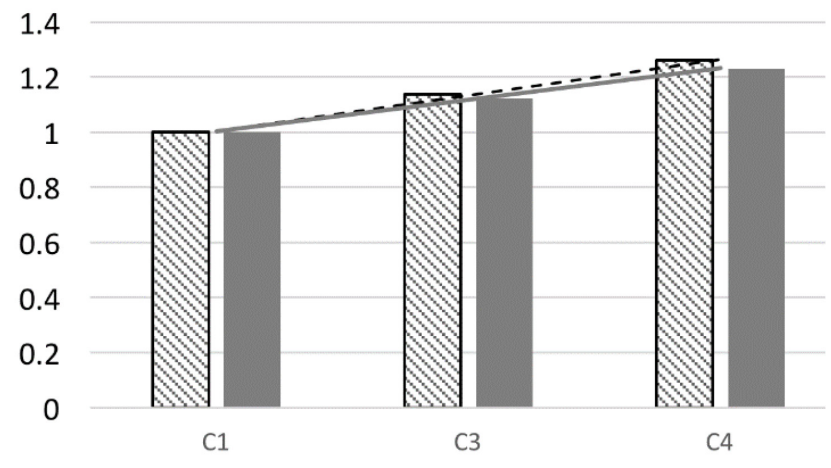

Fig. 2. Dynamics of change of comfort factor of investigated persons under the influence of samples of modified materials: (a) before washing; (b) after washing.

As it can be seen from the diagrams, after the modification of the samples, there is a tendency to the improvement of the comfort of the organism of the subjects. This tendency persists after three washing cycles as well.

It is established that all textile clothes in the environment of interaction with the person $\mathrm{C} 2, \mathrm{C} 3, \mathrm{C} 4$ exert energy and information influence on the organism of the studied persons. Given the purpose of these clothes, it is important to choose the clothes with the highest coefficient of comfort for the functional state of the body of the subjects (Tables 1,2). As visible, this option is a sample modified by impregnation of the textile material with citric acid and subsequent spraying of the medicinal peony nano-solution.

\section{Conclusions}

The paper suggests the method of provision of antimicrobial properties to textile materials using the solution of medicinal peony tincture. The use of vegetable raw materials in the creation of antimicrobial textiles is advantageous due to its availability, as well as, in most cases, its low toxicity, lack of habituation and negative side effects.

The technique of applying a phyto-preparation to a textile canvas has been developed. It has been found that it is expedient to use the method of atomization of the solution and structural destruction of the fiber by acids for the stable fixing and uniform distribution of the nanoparticles of the preparation on the surface of the textile web. This method prevents the rapid leaching of nanoparticles from the fabric surface during operation and washing.

As textile materials play an important role in the formation of the energy flows of the "man-clothesenvironment" system and such influence can be inert, positive or negative, the evaluation of the energyrelated impact of modified materials on the functional state of organs and systems of human organs using the wave medicine method is carried out.

It has been established that the medicinal materials obtained as a result of the modification of the peony solution exert a positive influence on the energy state of the person and activate processes in the body responsible for the immune system. This makes it possible to believe that these materials actively protect the body from exposure to pathogenic microflora.

Also, the method of energy information diagnostics determines the resistance to washing achieved by the modification of the antimicrobial effect. After three cycles of washing, citric acid modified with peony 
solution exerts a more active effect on the organism of the subjects compared to those modified with only peony solution.

Therefore, the results obtained in this paper contribute to the spread of the use of "green technologies" for the manufacture of textile materials with antimicrobial properties. Considering the potential danger of modified materials for human health, it is also important to use the method of complex analysis of the influence of materials on the functional state of the body.

\section{References}

[1] Abaeva, L. F.; Schumskyi, V. I.; Petritskaya, E. N. Nanoparticles and nanotechnology in medicine today and tomorrow. Clinical Medicine Almanac, 2010, 22, pp. 10-17.

[2] Erokhina, E.V. Synthesis of ultrafine copper and silver particles to protect textile materials from biodegradation. Physics of fibrous materials: structure, properties, high technology and materials, 2015, 1, pp. 88-91.

[3] Krichevsky, G. E. Nano, bio, chemical technology and production of new generation of fibers, textiles and clothing: monograph; 2011, Moscow.

[4] Galik, I. S., Semak, B. D. The use of nanotechnology for the medical textiles production. Bulletin of KNUTD, 2014, 3 (77). pp. 176-186.

[5] Matveytsova, D. S. Development of technology of final processing in textiles using silica nanoparticles, Doctoral dissertation, Kherson national University. 2017, Kherson.

[6] Shahid-ul-Islam; Shahid, M.; Mohammad, F. Perspectives for natural product based agents derived from industrial plants in textile applications - a review. Journal of Cleaner Production, 2013, 57, pp. 2-18.

[7] Bereznenko, N. P.; Wislenko, V. G.; Bandura, N. G. Creation of antimicrobial textile materials based on bast fibers and modified synthetic threads. Bulletin of KNUTD, 2005, 5, pp. 22-24.

[8] Dobrovolskaya, A. V.; Paliy, G. K.; Kryzhanivska, A. V. Using of natural dye for destination color and antimicrobial properties to textile materials. Light industry, 2008, 4. pp. 46-47.

[9] Herbal antibiotics. Available online: http://www.disbak.ru/php/content.php?id=4080

[10] Fedotkin, I. M. Notes on the theory of information-wave medicine (IVT, BRT, Moro therapy, VRT, SCENAR-T, OLM-1, Fractal-metric applicators) / Fedotkin I.M. - K.: Publishing house "Himjest", 2003, p. 40.

[11] Bereznenko, N.; Bereznenko, S.; Pawłowa, M.; Jancałowskij, O.; Vlasenko, V. Influence of textile materials on the functional state of human body - assessment; Towaroznawcze Problemy Jakosci, 2011, 4, pp. 59-65.

[12] Kislichenko, V. S., Zhuravel, I. O., Burda, N. E., Sakhatskaya, I. M. Antimicrobial drug; Utility model patent № 88422, МПК А61K 35/00, 11.03.2014.

[13] Manual evaporator Steam\&Go. Available online: https://www.philips.ua/c-p/GC361_20/steam-go-handheldgarment-steamer.

[14] Zhdanova, O.; Bereznenko; S.; Bereznenko, N.; Novak, D. Textile materials manufacturing features with the use of antimicrobial additives. Vlakna a Textil, 2017, 4, pp. 41-46.

[15] Pashkin, O. V.; Soroka, S. O. Method for determination the influence of biologically active substances on human skin. 2018, pp. 362-365.

[16] Buhantsova, L.; Luschevska, O.; Troyan, O.; Krasniuk, L.; Yantsalovskyi, O. Formation of the package of materials of adaptive multifunctional clothing. Technology Audit and Production Reserves, 2017, 3.3 (35), 412.

[17] Bereznenko M. P.; Vlasenko V. I.; Yantsalovsky O. Y. Investigation of the influence of textile materials on the energy-information state of human body. Collection of scientific works Sworld, 4 (32), pp. 31-38.

[18] Luschevskaya, O. M.; Yantsalovsky, O. Y.; Trojan, O. M. Method for evaluation the comfort of textile materials; Patent №35944, MПК G01 N33/36, 10.10.2008. 